\title{
Experimental investigation on the response of UHP(FR)C at high stress-rates under compression
}

\author{
Ezio Cadoni ${ }^{1, *}$, Matteo Dotta $^{1}$, Daniele Forni ${ }^{1}$, Gianmario Riganti ${ }^{1}$, and Nicoletta Tesio ${ }^{1}$ \\ ${ }^{1}$ DynaMat SUPSI Laboratory, University of Applied Sciences and Arts of Southern Switzerland, Via \\ Francesco Catenazzi 23, 6850 Mendrisio, Switzerland.
}

\begin{abstract}
Understanding the dynamic response of Ultra-High Performance Fibre-Reinforced Concrete has important implications for engineering applications, including protective structures and critical infrastructures. It is wellknown that the loading rate affects both material failure mechanism and mechanical properties such as strengths and absorbed energy. Moreover, materials properties are influenced by stress confinement, which usually occurs in a real structure. The aim of this preliminary experimental campaign was to analyse the behaviour of the dynamic response of UHPFRC and its matrix under compression considering a pre-compression state of $56.5 \mathrm{MPa}$ (about $1 / 3$ of the failure stress). Compression at high stress rate $(1.5 \mathrm{TPa} / \mathrm{s})$ were carried out on cylindrical specimens with diameter of $30 \mathrm{~mm}$ and three different heights of 30,45 and $60 \mathrm{~mm}$, respectively. An increment of strength and fracture time has been observed while increasing of the length of the specimen and a slight reduction of both quantities with the introduction of fibres for the longer specimens. The experimental results are analysed and discussed with the aim to better understand the mechanical behaviour of UHPFRC materials in case of dynamic event under service loading conditions and to study the size-effect on the material response.
\end{abstract}

\section{Introduction}

Dynamic loads (impact, blast, strong earthquake, etc) are accidental loads acting on building and infrastructures designed to withstand both service and accidental loads. The state of stress in the component materials will results from the combination of those produced by both quasi-static and dynamic loads. For a better comprehension of these phenomena it is necessary to subject the test specimen to static (mono-bi-tri-axial) state of stress prior to the impact loading. For this purpose a new experimental device was developed, named 3DModified Hopkinson Bar (3D-MHB) [1-3]. The testing campaign carried out by means of the 3D-MHB device was addressed to analyse the behaviour of the dynamic response of UHPFRC in compression aimed at analysing precompression state and by varying the size of the specimen. The pre-compression state $(56,5 \mathrm{MPa})$ was fixed at about $1 / 3$ of the quasistatic failure stress. The experimental results are analysed and discussed with the aim to better understand the mechanical behaviour of UHPFRC materials in case of dynamic event under service loading conditions and considering the size effect on the material response.

\footnotetext{
*e-mail: ezio.cadoni@supsi.ch
} 


\section{Materials and specimens}

The materials analyzed in this research are commercially available Ultra-High Performance Fibre-Reinforced Concrete products characterized by very high strength and durability. These outstanding caracteristics are due to highly resistant matrix (equivalent water/cement ratio equal to 0,17 ) and to high percentages of steel fiber reinforcement, hence special mechanical properties such as very high values of compression, flexural, and tensile strength are achieved. By adding high carbon straight steel fibers, $13 \mathrm{~mm}$ long with a $0.20 \mathrm{~mm}$ diameter (aspect ratio $1 / \mathrm{d}$ equal to 65 ) with $3 \%$ in weigth the following characteristics after 28 days are reached: elastic modulus $=51 \mathrm{GPa}$; density $=2473 \mathrm{~kg} / \mathrm{m}^{3}$, flexural strength $=37 \mathrm{MPa}$; compression strength $=197 \mathrm{MPa}$. Three different specimen geometries have been used, i.e. cilinders having $30 \mathrm{~mm}$ of diameter with height of 30,45 and $60 \mathrm{~mm}$ (see Figure 1). For the sake of brevity the matrix material is hereinafter referred as UHPC and the fibre-reinforced material as UHPFRC.

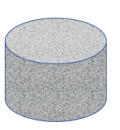

$\mathrm{h} / \mathrm{d}=1$

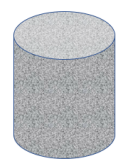

$h / d=1.5$

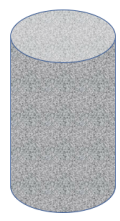

$\mathrm{h} / \mathrm{d}=2$

Figure 1. Geometry of the specimen under considerations.

\section{Experimental set-up}

The experiments have been carried out by means of the 3D-MHB experimental device [1-3] installed at the DynaMat Laboratory. It acts as a modified Hopkinson bar [4-10], with a pretensioned cylindrical bar, input and output bars of equal square cross-section with a $50 \mathrm{~mm}$ side. All bars are made of aged maraging steel. The pre-compression state can be imposed by means of a hydraulic actuator of $2 \mathrm{MN}$ at the end of the output bar. The dimensions of the three bars are reported in Figure 2. The total length of the 3D-MHB apparatus along the impact axis is of $7.82 \mathrm{~m}$. The length becomes $8.80 \mathrm{~m}$ when the bumper system is installed. By pulling the pre-tensioned bar, by means of another hydraulic actuactor of $4 \mathrm{MN}$, a rectangular loading pulse of $2 \mathrm{MN}$ amplitude and $800 \mu$ s duration can be generated.

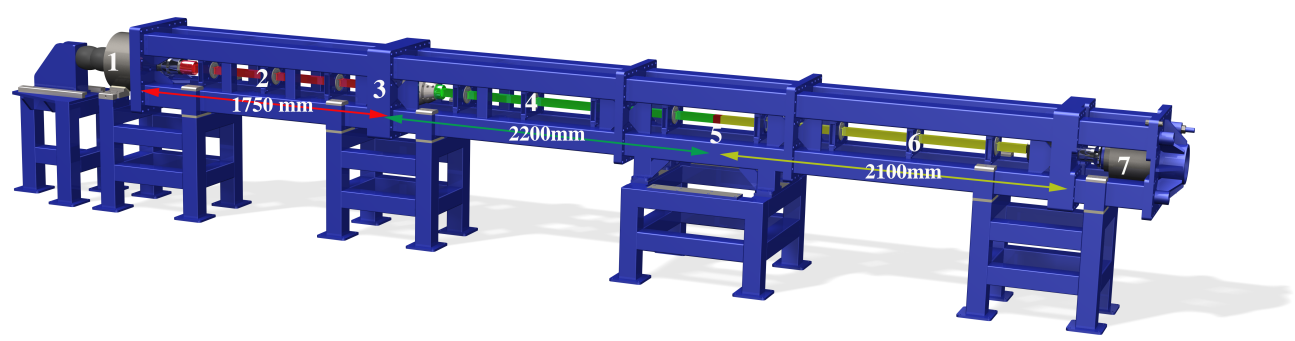

Figure 2. Experimental 3D-MHB device. 
Table 1. Experimental plan.

\begin{tabular}{lccccc}
\hline material & $\mathrm{H}=30 \mathrm{~mm}$ & $\mathrm{H}=45 \mathrm{~mm}$ & $\mathrm{H}=60 \mathrm{~mm}$ & pre-compression & pre-load \\
\hline UHPC & 3 & 3 & 3 & $40 \mathrm{kN}$ & $500 \mathrm{kN}$ \\
UHPFRC & 3 & 3 & 3 & $40 \mathrm{kN}$ & $500 \mathrm{kN}$ \\
\hline
\end{tabular}

The operative sequence in order to carry out a test using the 3D-MHB is as follows (refers to Figure 2): (i) A quasi-static stress state is applied to the UHPC specimen by the hydraulic actuator placed at the end of the output bar (7); (ii) By means of the principal hydraulic actuator (1) the pre-tensioned bar (2) is pulled till the established preload value. At this moment, this load is resisted by the fragile bolt, the pre-tensioned bar and the contrast ring (3). Because of the elastic movement of the entire system the pre-load on the specimen have to be checked and adjusted by the actuator (7); (iii) An adequate mechanical system ensures the bolt to be loaded without any influence to the rest of the measurement apparatus. In the 3D-MHB, the failure of the fragile bolt gives rise to a rectangular square pulse propagating into the input bar (4) and output bar (6) which loads dynamically the specimen (5) until failure of the specimen occurs; (iv) The strain gages on the input and output-confinement bar record the incident, reflected and transmitted waves that allow the definition of the equivalent stress-strain curves in analytical terms.

In Figure 3 the experimental set-up and a specimen before and after failure.

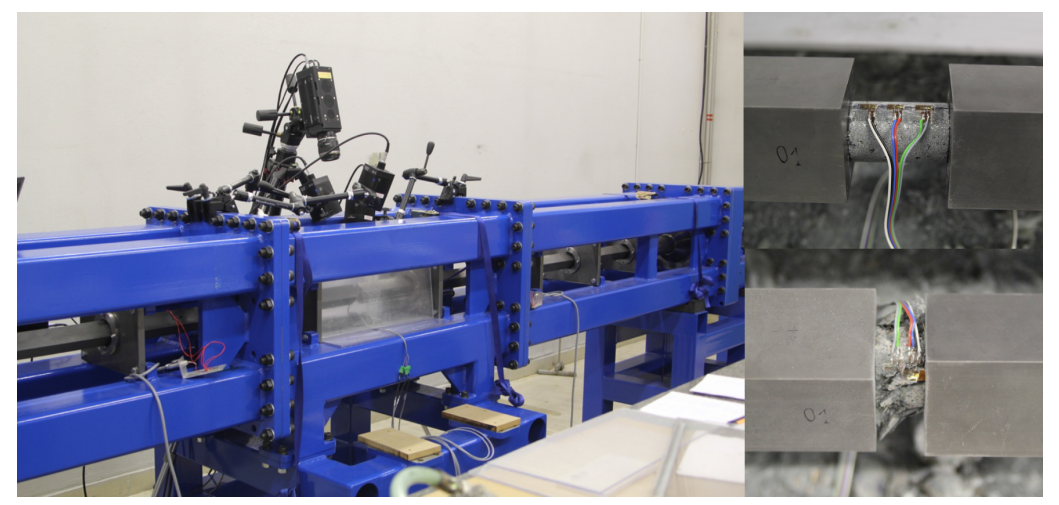

Figure 3. Experimental set-up and specimen appearance before and after failure.

\section{Preliminary results}

This preliminary experimental campaign has been designed in order to highligth the influence of the specimen size on the compressive response of a preloaded UHPFRC and its matrix (UHPC) samples. In Table 1 the experimental plan is summarized, at least 3 tests for each materials and conditions were carried out.

In Table 2 the results obtained on cylindrical UHPC and UHPFRC (3\%) specimens with diameter of $30 \mathrm{~mm}$ and three different height $(30,45,60 \mathrm{~mm})$ are reported, as a result three different H/D ratios 1:1, 1:1.5 and 1:2 were investigated. Under the same initial conditions, it has been observed an increment of the strength of the specimen as well as a growth of the fracture time. A slight reduction of the stress rate (due to the length of the specimen) can be appreciated. These results show how the specimen length influences the material response 
Table 2. Results obtained under the same pre-load and pre-strain.

\begin{tabular}{llllll}
\hline material & $\begin{array}{l}\text { length } \\
(\mathrm{mm})\end{array}$ & $\begin{array}{l}\text { stress-rate } \\
(\mathrm{GPa} / \mathrm{s})\end{array}$ & $\begin{array}{l}\text { strength } \\
(\mathrm{MPa})\end{array}$ & $\begin{array}{l}\text { fracture time } \\
(\mu \mathrm{s})\end{array}$ & $\begin{array}{l}\text { failure time } \\
(\mu \mathrm{s})\end{array}$ \\
\hline UHPC & 30 & $1567(135)$ & $518(35)$ & $283(29)$ & $402(27)$ \\
UHPC & 45 & $1489(41)$ & $549(50)$ & $345(32)$ & $402(25)$ \\
UHPC & 60 & $1431(155)$ & $518(15)$ & $395(14)$ & $463(32)$ \\
\hline UHPFRC & 30 & $1738(91)$ & $551(41)$ & $299(70)$ & - \\
UHPFRC & 45 & $1503(238)$ & $557(38)$ & $344(44)$ & - \\
UHPFRC & 60 & $1557(117)$ & $562(10)$ & $354(44)$ & - \\
\hline
\end{tabular}

due to structural effects. In Figure 5 three sequences of photos of three tests performed on UHPC and UHPFRC specimens with different length are shown. These pictures highlight the different time of occurance of the fracture process.

Initially, the fibres act as discontinuities within the matrix and induce micro-crack propagation, but after they affect the post-peak behaviour acting as bridge elements between the two edges of the crack by joining them.
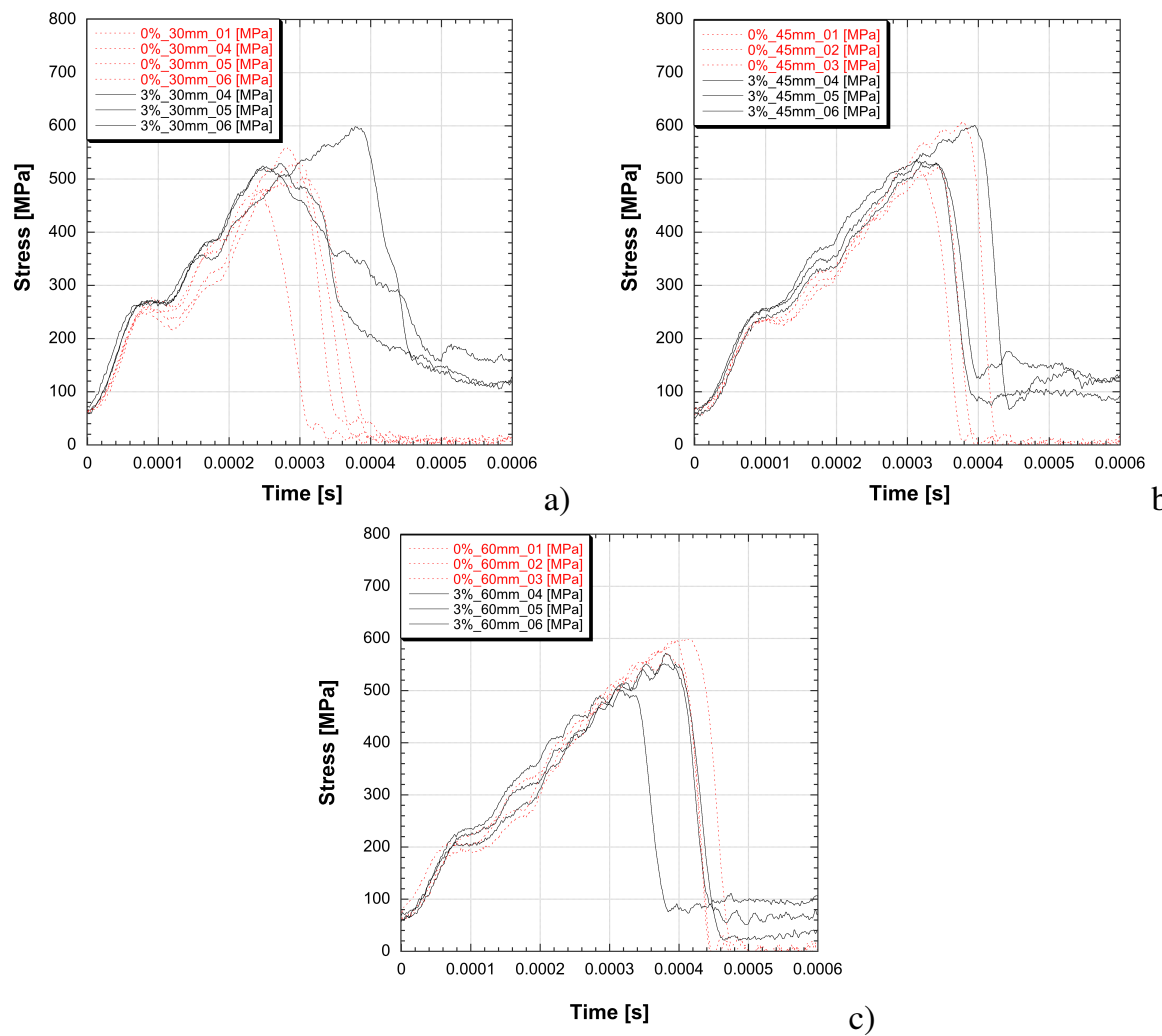

Figure 4. Comparison between UHPFRC and UHPC stress versus time curves: a) $30 \mathrm{~mm}$; b) $45 \mathrm{~mm}$ and c) $60 \mathrm{~mm}$ specimen. 

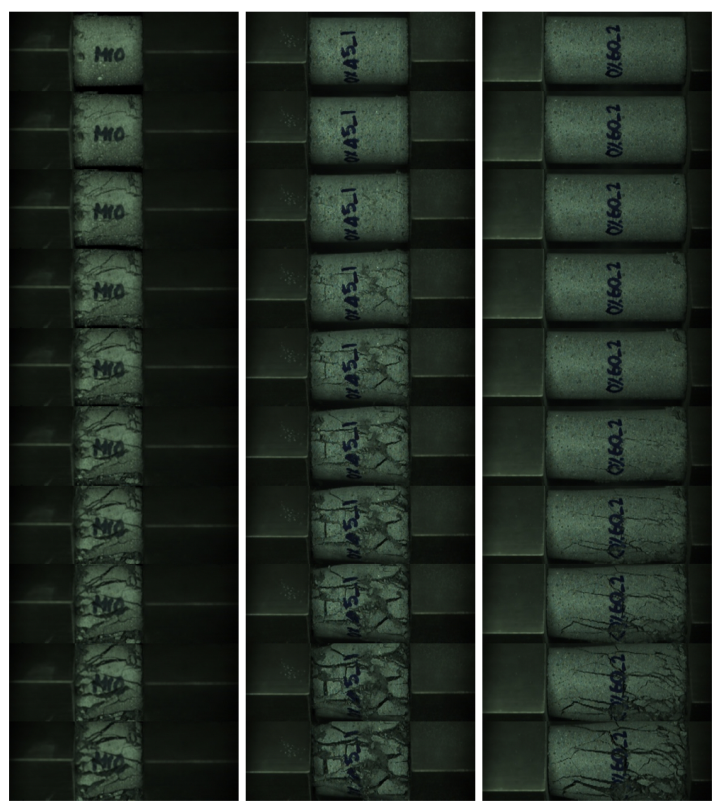

a)
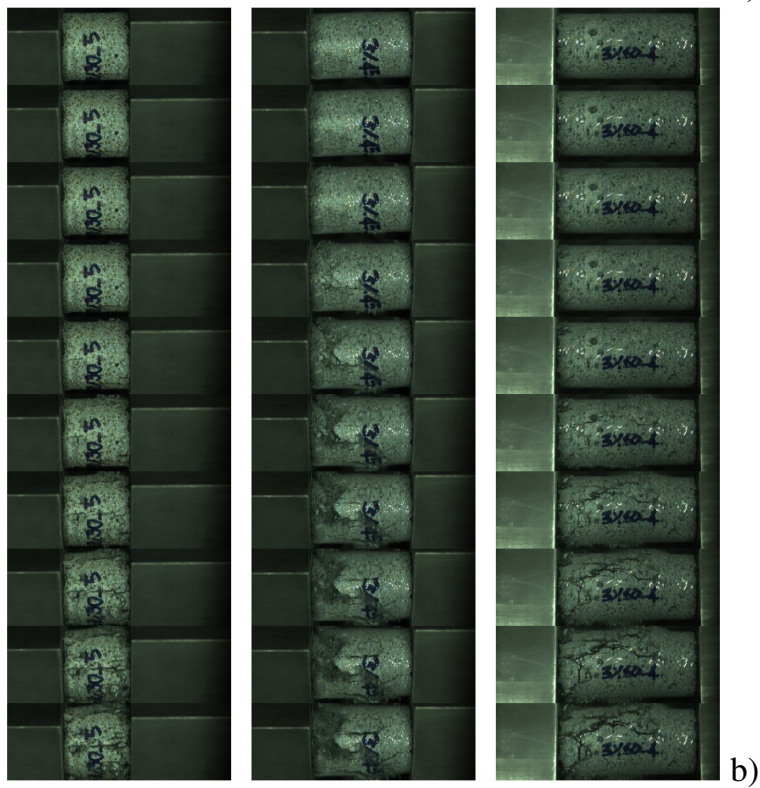

Figure 5. Comparison between matrix (a) and UHPFRC (b) failure

\subsection{Numerical assessment of the results}

In previous investigation [11] addressed to understand the tensile behaviour the numerical analyses were performed [12]. Here, the dynamic compression tests have been numerically simulated with a unique material model named DAMP (DAMage Propagation model) [13]. The application of the DAMP model allows to numerically reconstruct 3D-MHB dynamic compression test as well as static compression and tension experiments. The material model parameters are suitability to describe also tensile test. In Figure 6 the comparison between 
experimentally and numerically obtained stress versus time curves are shown both for $30 \mathrm{~mm}$ and $60 \mathrm{~mm}$ specimens. The suitability of tha DAMP model to reproduce 3D-MHB tests is evident. The DAMP material model is able to realistically reconstruct the structural response of materials with unique mechanical properties for a wide range of stress state from static to dynamic loading conditions considering different specimen size. Simultaneous reconstruction has been found critical when obtained with classical concrete material models [13].

In addition, some of the experiments have shown a no monotonic loading wave due to the experimental apparatus characteristics. Also in those cases the numerically reconstructed tests well reproduce the input and output signals obtained experimentally. The output signal adapts realistically to several input loading conditions and to different specimen length. The good agreement between experimental and numerical results are based on the fact that the DAMP material model strategy is based on the evaluation of the damage propagationloading wave and -specimen size interactions. Another important difference with respect to the state-of-the-art material models, rests into the prediction of the structural damage prior to the reaching of the maximal strength value.
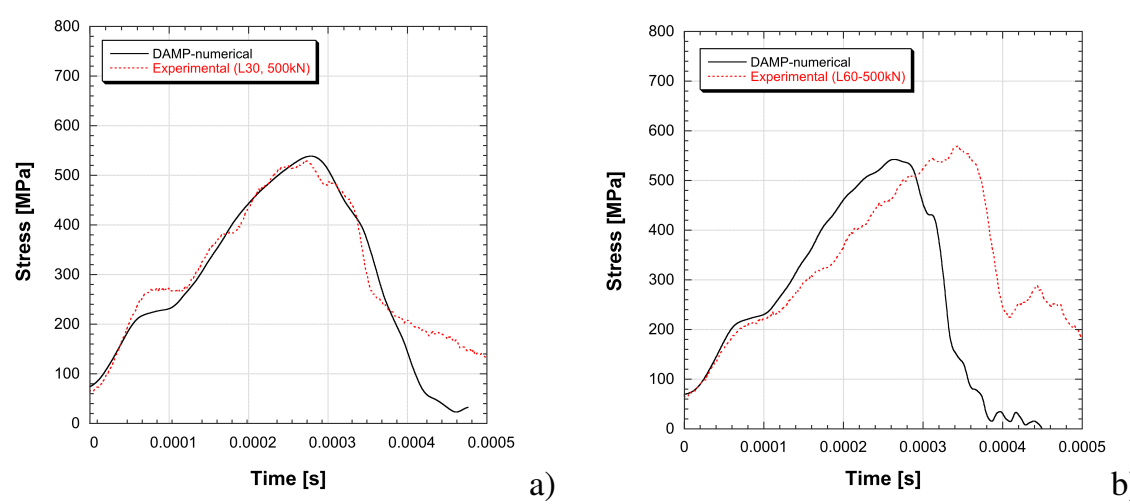

Figure 6. Comparison between numerical and experimental resutls: a) $30 \mathrm{~mm}$; b) $60 \mathrm{~mm}$ specimen.
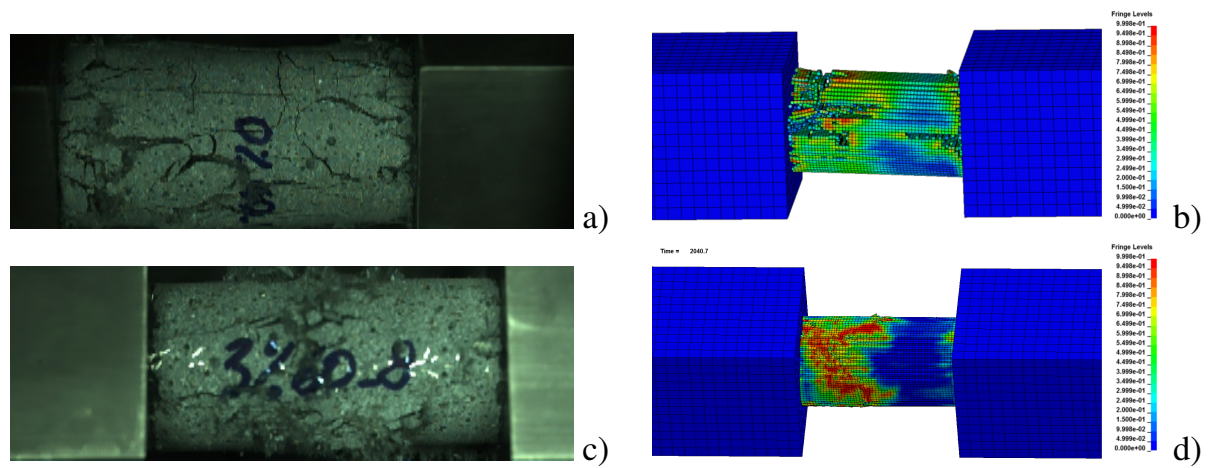

Figure 7. Comparison between photos at failure and numerical results on specimen with diameter 30 $\mathrm{mm}$ and height $60 \mathrm{~mm}$ of UHPC ( $\mathrm{a}$ and $\mathrm{b}$ ) and UHPFRC ( $\mathrm{c}$ and $\mathrm{d}$ ). 
Figures 7 b,d show colour contour of damaged elements (1-fully damaged, 0 intact material). They depict the initialization and propagation of prismatic fractures in case of UHPC (b) while a shear fracture is highlighted for UHPFRC (d).

\section{Concluding remarks}

The study of the dynamic behaviour of UHPFRC requires a broad experimental campaign in order to obtain information on the material response subjected to different loading conditions and under a wide range of strain rate. The experimental programme to determine the mechanical characteristics at high strain rate under compression considering a pre-existent compression state has been presented. Results have demonstrated the influence of the fibres on the compressive response as well as the specimen size effects on the strength and fracture time. In order to achieve a realistic structural assessment, in case of blast or impact, the use of numerical and analytical methods is needed. The obtained experimental results have been assessed by using the so-called DAMP material failure criteria that has proved to be a reliable model and that will be used for structural reliability assessment of building and structural elements against the effects of high dynamic loadings.

\section{References}

[1] E. Cadoni, C. Albertini, in Advances in Rock Dynamics and Applications (Taylor \& Francis, London, 2011) 79-104

[2] E. Cadoni, M. Dotta, D. Forni, G. Riganti, C. Albertini, EPJ WoC 94, 01031 (2015)

[3] E. Cadoni, M. Dotta, D. Forni, EPJ WoC 183, 02005 (2018)

[4] C. Albertini, E. Cadoni, K. Labibes, Exp. Mech. 39(2) 137-141(1999)

[5] E. Cadoni, K. Labibes, M. Berra, M. Giangrasso, C. Albertini, ACI Mat. J. 98 220-223 (2001)

[6] E. Cadoni, C. Albertini, G. Solomos, J. de Phys. IV 134 647-652 (2006)

[7] E. Cadoni, K. Labibes, C. Albertini, J. de Phys. IV 7(3) 915-920 (1997)

[8] E. Cadoni, D. Forni, E. Bonnet, S. Dobrusky, Const. Build. Mat. 218667 - 680 (2019).

[9] E. Cadoni, G. Solomos, C. Albertini, Mag. Concr. Res. 61(3), 221-230 (2009)

[10] E. Cadoni, G. Solomos, C. Albertini, Mag. Concr. Res. 65(11), 660-672 (2013)

[11] E. Cadoni, D. Forni, EPJ ST 225(2), 253-264 (2016)

[12] B. Luccioni, F. Isla, D. Forni, E. Cadoni, Cem. Conc. Comp. 91, 209 - 220 (2018)

[13] G. Riganti, E. Cadoni, Materials 13(21), 4976 (2020) 